\title{
Preparation and Characterisation of Cellulose Acetate and Carboxymethyl Cellulose from Edible Part and Peel of Green Banana (Plantain)
}

\author{
Sumyea Monira, Momota Akter, S. M. Mizanur Rahman* and M. Azizur Rahman* \\ Department of Chemistry, Dhaka University, Dhaka-1000, Bangladesh
}

(Received: 21 August 2016; Accepted: 17 January 2017)

\section{Introduction}

Being an agricultural country Bangladesh is blessed with various kinds of fruits and vegetables. Some of these fruits and vegetables are consumed as a whole and some are consumed partly leaving some wastes. Green banana is the most widely cultivated species of the genus Musa. The plant is a fast growing but the height of plant varies based on its location. Banana is a fruit of humid tropical regions of South East Asia with Indo-Bangla as one of its origin. The green banana has two parts one is called the edible part (inner shell) known as plantain and the other is the outer shell or non edible part which is known as peel and usually green in color. The edible parts are used as vegetables and the non edible parts or peel are not consumed by human and these are wastes. The peel contains mainly cellulose which is not digested by human organism because of the absence of the enzymes being capable of digesting this structure (glycosidic linkage). It was reported that green banana prior to repining stage contains slowly digestible starch known as resistant starch $^{1,2}$ which is not digested by human organism. Both the edible part and peel contains cellulosic materials. Cellulosic materials play a vital role in every step of present civilization and those are used in different form in our daily life.

So, it becomes very important to find out the new sources of cellulosic materials in most economic way for our present socio economic progress. So, the diversified uses of the different cellulosic sources may be explored for the development of present civilization as well as the economic condition. Nowadays, the isolation of cellulosic materials and preparation of their derivatives such as cellulose acetate, carboxymethyl cellulose, cellulose nitrate, cellulose sulfate have great importance for both in textile and in pharmaceutical Industries ${ }^{2}$. A large quantity of agricultural as well as food wastes are coming from various agriculture activities and agro processed industries. These agro waste materials are the cause of environmental pollution in the modern civilized society. It is a great problem to dispose of these waste materials properly. These agricultural wastes are mainly cellulosic materials so it may be used to convert different types of cellulosic derivatives such as nitrate, acetate, carboxymethyl cellulose (CMC) etc. as per the present demand. Sodium carboxymethyl cellulose (CMC) is a water soluble material like salt and this is used in large scale for detergent without any refinement. It is also used as drilling fluid and in the paper industry while CMC is used as a food additive for their higher degrees of purity. Cellulose acetate is used as raw materials for the production of plastic films and other polymeric materials like, transparent sheets, camera accessories, magnetic tapes, combs, telephone and electrical parts, etc. So, derivatization of cellulosic material of fruits skins and vegetables might be economically profitable and it will also eliminate the waste disposal problem.

\footnotetext{
*Author for correspondence. e-mail: smmrdb1981@ yahoo.com
}

\section{Experimental}

Solvents and chemicals All the solvents used in the present work were of analytical Grade (E. Merck and BDH) and were distilled before use.

\section{Materials and Methods}

\section{Sample collection and preparation}

Green bananas were collected from the local market of Dhaka city. The outer skins of the fruits (peel) were separated manually. The edible portion as well as the peel separately cut into small pieces, dried in open air followed by finally dried in an electric oven at $45^{\circ} \mathrm{C}$. After drying, the dried plant material was ground separately with grinder mill and stored at room temperature to carry out all the experiments.

Determination of ash content: Measured quantity (3.0 g) of each peel and edible part was taken separately in the previously cleaned, dried and weighed porcelain crucible and the ash contents were determined following standard method $^{3}$.

The ash contents of peel and edible part were found to be $6.59 \%$ and $3.06 \%$, respectively.

\section{Extraction of dried powder}

The dried powder $(40.0 \mathrm{~g})$ each of peel as well as edible portion were extracted separately with $(300 \mathrm{~mL})$ petroleum ether (b.p. $40-60^{\circ} \mathrm{C}$ ) under reflux condition for 30 minutes. After refluxing, the content of the flask was allowed to cool at room temperature and filtered. The whole process was repeated twice and the residue was dried in the air and marked as "extractive free powder". The percentage of extracts and extractive free powders of peel and edible portion were found to be $(7.1 ; 92.9)$ and $(5.4 ; 94$ $6)$, respectively.

\section{Delignification of extractive free powder}

The extractive free powders $10.0 \mathrm{~g}$ each of peel as well as edible part were suspended with water $(200 \mathrm{~mL})$ separately into two conical flask and their delignification were carried out following the standard method ${ }^{4}$. The resultant delignified powders obtained were termed as "hollocellulose" and it was found to be $78.0 \%$ and $90.0 \%$ for peel and edible portion of green banana, respectively.

\section{Preparation of carboxymethyl cellulose}

Measured quantity of hollocellulose of peel as well as edible part of green banana were converted into carboxymethyl cellulose (CMC) derivtives separately following the standard procedure ${ }^{5,6}$. Their percentage of conversions were found to be $85 \%$ and $70.7 \%$, respectively.

\section{Preparation of cellulose acetate}

Measured quantity of hollocellulose of peel and edible part of green banana were converted into cellulose acetate following the standard method ${ }^{7}$ and it was found to be $42.1 \%$ and $14.7 \%$ for the edible part and peel of green 
banana, respectively.

Determination of degree of substitution (DS)

Degree of substitution of the prepared acetate derivatives of holocelluluse of peel as well as edible part of green banana were determined separately by titrimetric $\operatorname{method}^{8}$. The values of DS of the fractions were found to be $39.2 \%$ and $0.4 \%$, respectively.

Spectroscopic Study of holocellulose, cellulose acetate, and carboxymethyl cellulose of peel and the edible part of green banana powder:

The IR spectra of holocellulose, its acetate and carboxymethyl derivatives of peel and edible part of green banana were recorded separately in $\mathrm{KBr}$ pellets using a Shimadzu IR-470 spectrophotometer. Characteristics absorption peaks for holocellulose and their acetate and carboxymethyl cellulose derivatives were identified and the absorption pattern was explained.

\section{Results and Discussion}

Green banana was collected locally; peel and the edible part were separated manually. These peels and edible parts were cut into small pieces, dried and powdered. The powders were separately extracted with petroleum ether. The extractive free powders of each part were separately delignified. Each of the hollocelluloses were separately acetylated and carboxy methylated and the degree of substitution of their acetate derivatives were determined. IR spectral study of their acetate and carboxymethyl cellulose was carried out. The amount of petroleum ether (b.p. 40$60^{\circ} \mathrm{C}$ ) extract of the peel $(7.1 \%)$ and edible portion $(5.4 \%)$, reveals that edible part contains lower proportion of soluble organic materials than that of peel. It was observed that the proportion of holocellulose in the peel was $78.0 \%$ which indicates that it was mainly composed of cellulosic materials $^{8}$. The hollocellulose of edible portion was $90.0 \%$ which was significantly high and this may be due to the presence of resistant $\operatorname{starch}^{1}$.

This result reveals that, both the peel and edible portion of green banana may be used as the sources of cellulosic materials, which are comparable to the other agro waste materials ${ }^{9-11}$. The degree of substitution of the acetate derivatives of the holocellulose of peel and the edible portion were found to be $39.2 \%$ and $0.4 \%$, respectively indicating that the cellulosic materials obtained from the peel of banana has been partially acetylated whereas that of the edible portion was almost not at all, that may be the indicative of the presence of resistant starch in edible portion $^{1,2}$.

Infrared spectral of the holocelluloses show the moderate to strong absorption peaks at 3778-3458 $\mathrm{cm}^{-1}$ (M), 2927-2924 $\mathrm{cm}^{-1}(\mathrm{~S})$ and at $1080-1020 \mathrm{~cm}^{-1}(\mathrm{~S})$ indicating the presence of $\mathrm{O}-\mathrm{H}$ stretching, $\mathrm{C}-\mathrm{H}$ stretching and $\mathrm{C}-\mathrm{O}$ stretching of sugar unit, respectively, but no distinct absorption peak for $\mathrm{C}=\mathrm{O}$ stretching was found. The absorption peak with strong intensity at around $1718-1637 \mathrm{~cm}^{-1}$ was found for $>\mathrm{C}=\mathrm{O}$ group of acetate and the absorption peak of $\mathrm{C}-\mathrm{O}$ stretching acetyl group at around $1107-1105 \mathrm{~cm}^{-1}$ was appeared. The other characteristic absorption peaks due to $\mathrm{C}-\mathrm{O}$ stretching of skeletal backbone were observed both holocellulose and its acetate derivative at the range of $1080-1020 \mathrm{~cm}^{-1}$ except in the case of acetate derivative of the edible portion of green banana, where nothing is observed in that region, that may be the indication of non-cellulosic materials present in edible portion, i.e. degraded starch which is termed as resistant starch. The characteristic absorption peaks with strong to moderate intensity for $\mathrm{O}-\mathrm{H}$ stretching (both free and bonded) identified in holocellulose and their acetate derivatives indicated that the inner portion has many free $\mathrm{OH}$ groups left in these derivatives. This finding suggests that the materials have been partially acetylated.

The IR spectral analysis of the carboxylmethyl cellulose derivatives of holocellulose shows the strong absorption bands at 1749 and $1619 \mathrm{~cm}^{-1}$ due to the asymmetric stretching and that of at $1402,1258, \mathrm{~cm}^{-1}$ for symmetric stretching of the carboxylate ion that present in this derivatives. The presence of these peaks is also giving the indication of successful derivatization of these two fractions. The strong absorption peak of $\mathrm{C}-\mathrm{H}$ stretching band in carboxymethyl cellulose derivatives was observed at 2958$2953 \mathrm{~cm}^{-1}$. The value of DS and the information obtained from IR spectral analysis it may be concluded that the successful partial acetylation of the cellulosic materials obtained from the peel and the edible portion of green banana fruit.

\section{Conclusion}

This results suggests that agro-wastes (outer skin of green banana and also edible portion might be used as source of cellulosic material which could be successfully converted into their derivatives (cellulose acetate and carboxymethyl cellulose), for their commercial and industrial utilization.

\section{References}

1. Yong-Cheng Shi Clodualdo, C. Maningat, 2013. E-BOOK, Resistant Starch: Sources, Application \& Health Benefits, ISBN: 978-1-118-52875-4,Wiley-Blackwell. Pages, 312.

2. http: // ChriskKresser.com / how-resistant-starch will to make you healthier and thinner.

3. www.tappi.org/19525.

4. Rowell, RM., 2005. Handbook of Wood Chemistry and Wood Composite, CRC Press, 62

5. Khundkar, MH. and AK, Bhattacharjee, 1964. Derivatisation of carboxymethyl cellulose, Pak. J. Sci. Ind. Res., 8, 89.

6. Jahan, I.A., F. Sultana, M.N.Islam, M.A. Hossain, and J. Abedin, 2007. Studies on indigenous cotton linters for preparation of carboxymethyl cellulose, B. J. Sci. Ind. Res., 42(1), 29-36.

7. Israel $\mathrm{AU}, \mathrm{IB}$ Obot, SA Umoren,V. Mkpenie and JE Asuquo, 2008. Production of cellulosic polymers from agriculture wastes, $E$ J. of Chem., 5(1), 81-85.

8. Filho GR, DS, Monteiro, CDS Meirele, RMND Assuncao, DA Cerqueira, HS Barud, SJL Rebeiro and Y. Messade, 2008. Synthesis and characterization of cellulose acetate produced from recycled newspaper. Carbohy. Poly., 73(1), 74-82.

9. Rahman, SMM, M.A. Rahman, T. Tasnim and K. Akter, 2006. Isolation of cellulosic materials from outer skin of Drumstick and Jarul Fruits and their derivatization. Dhaka Univ. J. Sci., 64(2), 177-178.

10. Rahman, M. A, T. Muslim, A. Saha, S. Akther, F. Rashid, M. R Afrin, N. Akter, and S. Debnath, 2014. Isolation of cellulosic material from waste fruits of Bangladwsh and their derivatization. Int. J. of Adv. in Phar. Biol. And Chem., 3(2), 2277- 4688.

11. Rahman, S.M.M, F. Akter, S. M. Rifat, T. Muslim, and M. A. Rahman, 2015. Isolation of Cellulosic Material from Drumstick Pulp and Outer Shell of Watermelon and Preparation of their acetate and carboxymethyl derivatives, Int. J. of Adv. in Phar.Biol. and Chem., 4(1), 218-222. 